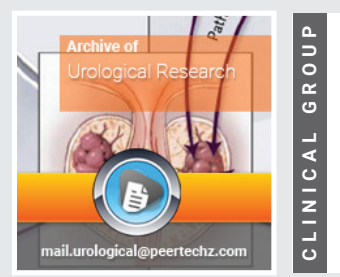

\title{
Classification in the diagnosis and treatment of organ damage caused by urogenital trauma in children
}

Received: 30 January, 2020

Accepted: 29 February, 2020

Published: 02 March, 2020

*Corresponding author: Abuzer Coskun, MD, Sivas Numune Hospital, Department of Emergency, Yesilyurt Mah. Sifa Street. Sivas, Turkey, Tel: + 9044444 58; Fax + 9034622395 30; Cep: +90 53215779 12; E-mail: dr.acoskun44@hotmail.com

ORCiD: https://orcid.org/0000-0003-4824-7021

https://www.peertechz.com

\section{Check for updates}

\author{
Cengiz Güney ${ }^{1}$ and Abuzer Coşkun ${ }^{2 *}$ \\ ${ }^{1}$ Cumhuriyet University Medical Faculty, Pediatric Surgery Clinic, Sivas, Turkey \\ ${ }^{2}$ Sivas Numune Hospital, Department of Emergency, Sivas, Turkey
}

\begin{abstract}
Background: This study aimed to determine the characteristics of the urogenital traumas that constitutes a small part of children who were admitted to the emergency department, the classification of the injured organ, the conditions associated with the diagnosis and treatment.
\end{abstract}

Material and Method: This retrospective cohort study included 254 patients younger than 18years of age who were admitted to the emergency department due to urogenital trauma between January 2014 and December 2018. Of these, 195(76.78\%) were male, with a mean age of 8years (range, 1-15years). The demographic characteristics of these patients, types of trauma, examination results, classification of injured organs, diagnosis and treatment results were evaluated.

Result: Of the patients, $241(94.88 \%)$ were blunt, $10(3.93 \%)$ were penetrating and $3(1.18 \%)$ were with iatrogenic trauma. Of the cases of trauma, $146(57.5 \%)$ were falling from a height lower than one meter, $23(9.1 \%)$ were fall from a height higher than one meter, and $38(17.3 \%)$ were inside and outside of a car traffic accident, $10(3.93 \%)$ were sharp object injury. $28(11 \%)$ patients had a kidney, $9(3.5 \%)$ had a ureteral, $24(9.4 \%)$ had bladder and $20(7.8 \%)$ had a urethral injury. $17(6.7 \%)$ of the cases were operated due to various reasons. The pelvic fracture was detected in all bladder injuries. Hematuria was seen in all cases.

Conclusion: Isolated urogenital traumas are rare and often accompany multiple organ injuries. Minor and major traumas are observed in the urogenital system in pediatric patients exposed to trauma. Urogenital traumas can also be seen in minor traumas. A thorough examination is required to avoid being overlooked.

\section{Introduction}

The frequency of genitourinary traumas occurring parallel to the technological developments in the world is increasing rapidly in children. The mortality rate of genitourinary trauma is very low; however, when long-term sequelae are taken into consideration, the importance of correct diagnosis and treatment can not be underestimated [1].

The urogenital system constitutes $3-10 \%$ of all child injuries. $90 \%$ of these cases are seen after blunt trauma. Penetrating injuries are more common in older children and constitute the other $10 \%$. In a very small part, iatrogenic injuries occur. When evaluating genitourinary traumas, other life-threatening cerebral, thoracic, abdominal and skeletal injuries should be considered [2-4].
The most common causes of blunt trauma of urogenital injuries are fall, rape, motor vehicle accidents, and sports injuries. Factors causing penetrating injuries are gunshot injuries and sharp object injuries [5].

Minor genital traumas that do not require surgical treatment constitute most of childhood genital trauma [6]. In female children, genital organ injury can easily be occurred due to tissue fragility in the prepubertal period [7]. While anterior urethra may be affected by traumas involving the penis in male children, the urethra is rarely affected by female children since it is short and mobile $[8,9]$.

Nowadays there are many studies on child trauma but we have not been able to detect any studies in the literature related to organ injury classification. Since the number of the studies on the relationship between trauma levels and organ injury in 
emergency department admissions, the relationship between post-traumatic complications and prognosis is very small, we aimed to determine these relationships in our study.

\section{Materials and methods}

\section{Study design and population}

This retrospective cohort study included 254 patients younger than 18years of age who were detected to have genitourinary trauma in the emergency department between January 2014 and December 2018. After the etiologic trauma factors, organ involvement and classification were determined, the patients were hospitalized in the pediatric surgery clinic. The cases excluded from the study were the causes of trauma within the first 24 hours, the patients that did not been taken direct radiographs required for the diagnosis, the patients who were not performed abdominal and pelvic Computed Tomography (CT) and/or Ultrasonography (US), and small household accidents and cuts. Demographic characteristics, trauma patterns, examination results, urogenital organ injuries, other organ injuries, hospitalization procedures, and results were evaluated.

Patients were classified in the study. In terms of trauma they were classified into 6 groups as; falling from a height up to one meter $(-1 \mathrm{mF})$ 'these are usually falling from swing, bicycle, staircase and a height not more than one meter such as wall, bunk beds', falling from a height of one meter and higher $(+1 \mathrm{mF})$, inside of the car (ICTA) and outside of the car (OCTA) traffic accidents, Sharp Object Injuries (SOI) and iatrogenic injuries. Kidney injury was classified into 5 groups as no injuries, contusion, laceration, subcapsular and parenchymal injuries. The presence of ureteral injury was evaluated. Bladder injury was classified into 4 groups as no injuries, contusion, intraperitoneal and extraperitoneal. Urethral Injury was classified into 4 groups as no injuries, anterior, posterior and laceration. The American Association for the Surgery of Trauma (AAST) organ damage scale committee, which is widely used today in the classification of the renal, ureteral, bladder and urethral trauma, was used [10]

Genital organs were classified into two groups as male and female. The male genital organ injury was classified as scrotum, testicular and penis injury. In these classifications, subgroups were formed according to the type of injury. Female genital organs were classified into two groups as perineal and vaginal injuries.

Pelvic radiographs, abdominal and/or pelvic CT and/ or abdominal and pelvic US were requested in pelvic and intraabdominal traumas in patients. The scrotal US was requested in blunt scrotal traumas and cystography was performed in all patients with suspected bladder trauma. Retrograde urethrography was performed in all cases with suspected urethral trauma.

\section{Statistical analysis}

The data obtained from this study were analyzed using SPSS 20 package program. In the evaluation of the data, crosstables of the data are arranged by specifying the arithmetic mean, \pm standard deviation, number, and percentage of individuals. To determine the relationship between trauma types and urogenital injuries, Spearman's Rho coefficient was calculated and the error level was calculated as 0.05 .

\section{Result}

This retrospective cohort study included 254 patients younger than 18years of age who were admitted to the emergency department due to urogenital region trauma between January 2014 and December 2018. Of these, 195(76.78\%) were detected to be male and 59(23.22\%) were female and the mean age was 8 years (range, 1-15years). The sex distribution of the patients was given in Figure 1 and the distribution of the trauma by gender and age was given in Table 1 . When we look at the distribution of trauma types according to age, it was seen that $-1 \mathrm{mF}$ was higher in all types of trauma (Figure 1).

The most commonly seen type of trauma was $-1 \mathrm{mF}$. It was found that there was the least injury among all traumas in this type of fall. The OCTA was in second place and it was followed by $+1 \mathrm{mF}$. The most frequent injury was seen after the OCTA, followed by after $+1 \mathrm{mF}$ injuries. Groups with the least injury were the iatrogenic and SOI groups.

Kidneys and ureters did not show any injury in $-1 \mathrm{mF}$, SOI and iatrogenic traumas. Most of the injuries were in the OCTA, followed by $+1 \mathrm{mF}$. The most frequent injuries were Type 1 with
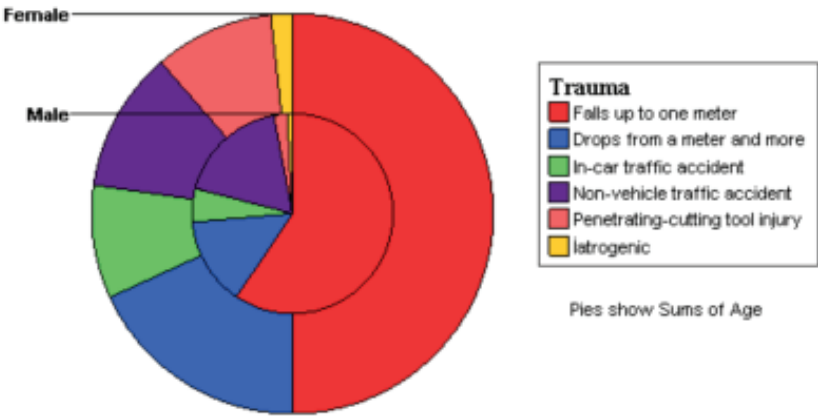

Ples show Sums of Age Figure 1: Types of trauma and gender distribution by age.

Table 1: Distribution of age according to gender and trauma types.

\begin{tabular}{|c|c|c|c|c|c|}
\hline \multicolumn{7}{|c|}{ Age Distribution } \\
\hline Age & $\mathbf{n}$ & Minimum & Maximum & Mean & SD \\
\hline Gender & 254 & 1 & 15 & 8.27 & 3.26 \\
\hline $\begin{array}{c}\text { Female } \\
\text { Male }\end{array}$ & 59 & 1 & 15 & 7.76 & 3.34 \\
\hline Trauma & 195 & 1 & 15 & 8.42 & 3.22 \\
\hline $\begin{array}{c}\text {-1mF } \\
+1 \mathrm{mD}\end{array}$ & 146 & 1 & 15 & 8.25 & 3.27 \\
\hline ICTA & 19 & 1 & 14 & 8.80 & 3.44 \\
\hline $\begin{array}{c}\text { NCTA } \\
\text { PCTI }\end{array}$ & 40 & 2 & 14 & 6.89 & 3.33 \\
\hline latrogenic & 10 & 3 & 15 & 8.67 & 2.95 \\
\hline
\end{tabular}

SD: Standard Deviation; $-1 \mathrm{mF}$ : Falls up to one meter; +1mD: Drops from a meter and more; ICTA: In-Car Traffic Accident; NCTA: Non-Vehicle Traffic Accident; PCTI: Penetrating-Cutting Tool Injury.

Citation: Güney C, Coşkun A (2020) Classification in the diagnosis and treatment of organ damage caused by urogenital trauma in children. Arch Urol Res 4(1): 
8(3.6\%) cases, followed by Type 2 and Type 3 with $6(2.4 \%)$ cases. Type 4 kidney injury was detected in two cases. Renal injuries were most commonly associated with the ureteral injury. The ureteral trauma was most frequently seen with OCTA and SOI. Two of $8(3.6 \%)$ patients with ureteral injury had Type 4 . Hematuria was present in $29(78.4 \%$ ) of the patients with renal or ureteral injury (Table 2 ).

Contusion was seen to be the most frequent injury in the bladder and urethra. The most common cause of bladder contusion was found to be OCTA and $+1 \mathrm{mF}$. Type 2 damage was detected in 7 patients and Type 4 in 4 patients with bladder injury. In the urethra, there were Type 1 injuries in 4 cases, Type 2 in 9 cases, Type 3 in 6 cases and Type 5 in 1 case. Hematuria was detected in all bladder and urethral injuries (Table 3 ).

Table 2: Distribution of renal and ureteral injuries by trauma types.

\begin{tabular}{|c|c|c|c|c|c|c|c|}
\hline \multicolumn{8}{|c|}{ Trauma Types } \\
\hline & & $\begin{array}{l}-1 \mathrm{mF} \\
\mathrm{n}(\%)\end{array}$ & $\begin{array}{l}+1 \mathrm{mD} \\
\mathrm{n}(\%)\end{array}$ & $\begin{array}{l}\text { ICTA } \\
\text { n (\%) }\end{array}$ & $\begin{array}{l}\text { NCTA } \\
\text { n (\%) }\end{array}$ & $\begin{array}{l}\text { PCTI } \\
\text { n (\%) }\end{array}$ & $\begin{array}{c}\text { İatrogenic } \\
\text { n (\%) }\end{array}$ \\
\hline \multirow{6}{*}{ Kidney } & None & $146(57.5)$ & $23(9.1)$ & 18(7.1) & $26(10.2)$ & $10(3.9)$ & $3(1.2)$ \\
\hline & Contusion & $0(0)$ & $7(2.8)$ & $0(0)$ & $4(1.6)$ & $0(0)$ & $0(0)$ \\
\hline & Laceration & $0(0)$ & $4(1.6)$ & $1(.4)$ & $4(1.6)$ & $0(0)$ & $0(0)$ \\
\hline & Subcapsular & $0(0)$ & $1(.4)$ & $0(0)$ & $5(2.0)$ & $0(0)$ & $0(0)$ \\
\hline & Parenchymal & $0(0)$ & $1(.4)$ & $0(0)$ & $1(.4)$ & $0(0)$ & $0(0)$ \\
\hline & Total & $146(57.5)$ & $36(14.2)$ & $19(7.5)$ & $40(15.7)$ & $10(3.9)$ & $3(1.2)$ \\
\hline \multirow{3}{*}{ Ureter } & None & $146(57.5)$ & $35(13.8)$ & $19(7.5)$ & $35(13.8)$ & $7(2.8)$ & $3(1.2)$ \\
\hline & Yes & $0(0)$ & $1(.4)$ & $0(0)$ & $5(2.0)$ & $3(1.2)$ & $0(0)$ \\
\hline & Total & $146(57.5)$ & $36(14.2)$ & $19(7.5)$ & $40(15.7)$ & $10(3.9)$ & $3(1.2)$ \\
\hline
\end{tabular}

Table 3: Distribution of bladder and urethral injury by trauma types.

\begin{tabular}{|c|c|c|c|c|c|c|c|}
\hline \multicolumn{8}{|c|}{ Trauma Types } \\
\hline & & $\begin{array}{l}-1 \mathrm{mF} \\
n(\%)\end{array}$ & $\begin{array}{c}+1 \mathrm{mD} \\
\mathrm{n}(\%)\end{array}$ & $\begin{array}{l}\text { ICTA } \\
\text { n (\%) }\end{array}$ & $\begin{array}{l}\text { NCTA } \\
\mathrm{n}(\%)\end{array}$ & $\begin{array}{l}\text { PCTI } \\
\text { n (\%) }\end{array}$ & $\begin{array}{c}\text { İatrogenic } \\
\text { n (\%) }\end{array}$ \\
\hline \multirow{5}{*}{ Bladder } & None & $146(57.5)$ & $28(11)$ & $17(6.7)$ & $29(11.4)$ & $8(3.1)$ & $2(.8)$ \\
\hline & Contusion & $0(0)$ & $4(1.6)$ & $1(.4)$ & $5(2.0)$ & $2(.8)$ & $1(.4)$ \\
\hline & Intraperitoneale & $0(0)$ & $3(1.2)$ & $1(.4)$ & $3(1.2)$ & $0(0)$ & $0(0)$ \\
\hline & Extraperitoneale & $0(0)$ & $1(.4)$ & $0(0)$ & $3(1.2)$ & $0(0)$ & $0(0)$ \\
\hline & Total & 146(57.5) & $36(14.2)$ & 19(7.5) & 40(15.7) & 10(3.9) & $3(1.2)$ \\
\hline \multirow{5}{*}{ Urethra } & None & 146(57.5) & 31(12.2) & 18(7.1) & $32(12.6)$ & $7(2.8)$ & $0(0)$ \\
\hline & Laceration & $0(0)$ & $0(0)$ & $0(0)$ & $4(1.6)$ & $0(0)$ & $0(0)$ \\
\hline & Anterior & $0(0)$ & $3(1.2)$ & $0(0)$ & $2(.8)$ & $1(.4)$ & $3(1.2)$ \\
\hline & Posterior & $0(0)$ & $2(.8)$ & $1(.4)$ & $2(.8)$ & $2(.8)$ & $0(0)$ \\
\hline & Total & 146(57.5) & $36(14.2)$ & 19(7.5) & $40(15.7)$ & 10(3.9) & $3(1.2)$ \\
\hline
\end{tabular}

In the analysis of trauma types for male and female genital organ injury; the most common injuries were observed to occur as a result of $-1 \mathrm{mF}$. These were scrotal skin, testicular and penile lacerations. Scrotal rupture, testicular rupture, and penile fracture were detected in 3,2 and 1 cases, respectively. Perineal skin laceration was most frequent in women, perineum rupture was detected in 9 cases, a vaginal tear in 5 patients, and hymenal tear associated with the vaginal tear in 2 patients (Table 4).

According to the results obtained in Spearman's Rho test, correlation coefficients were associated between trauma types and kidney, ureteral, bladder and urethra injuries. These statistically significant coefficients were found to be significant only as relation criteria (Table 5).

\section{Discussion}

Human life begins with labor that is a trauma and trauma is encountered until the child completes his/her development, from the first breath $[11,12]$. Today, trauma is a leading cause of child mortality [13]. Permanent disabilities occurring more frequently than trauma-related deaths and decreased quality of life are also an important health problem [14].

Traumas in children are classified into 2 groups as blunt traumas (vehicle accidents, falling, play, sports, crushing) and sharp object traumas. Child injuries are different from adults due to anatomical and physiological features. Sense organs in children are close to each other and to the surface, the possibility of multiple organ injury is higher. Other reasons are that their bone and muscle structures do not adequately protect the internal organs. Since the bones are flexible, internal organ damage can be seen without fracture. Because the body surface is large and subcutaneous fat is thin, the heat and fluid loss are high. Also, children are more affected psychologically by trauma.

Perirenal adipose tissue is not well developed in the kidneys, so it can not absorb the direct force applied to the abdomen and protect the organ. The fibrous capsule tries to prevent the fragmentation of the kidney tissue due to its being elastic [15]. However, vascular structures and ureters restrict the movement of the kidney [16]. The most frequently injured organ due to trauma in the urogenital system is the kidney. There are renal injuries in $8-10 \%$ of cases with abdominal trauma [17]. The most common causes of renal injury are blunt trauma caused by falling from a height and traffic or game accidents. Sharp object injuries are extremely rare compared to adults $[2,3]$.

Our cases of renal and ureteral injury in our study were blunt traumas that frequently occurred as a result of $+1 \mathrm{mF}$ and traffic accidents. There was no sharp object injury case or no injury cases due to $-1 \mathrm{mF}$ and iatrogenic causes. Falling from a height and OCTA comprised 27 (96.4\%) of all renal injuries.

Karakoc [18] and Soto [19] et al., state that stage 1 renal trauma is the most common observed injury via computerized tomographic examination technique, with a prevalence of $85 \%$. Streaking in the perirenal adipose tissue, a hyperdense subcapsular hematoma can be observed. Large size subcapsular hematoma may cause pressure in the parenchyma. In contrasted abdomen tomography, the contusion areas are as irregularly bordered, oval or round shaped hypodense areas.

In our study, the most common observed injury is stage 1 minor contusion. Of these, $7(25 \%)$ were $+1 \mathrm{mF}$ and $4(14.3 \%)$ were blunt trauma due to OCTA. These cases were followedup by bed rest. No complications were observed. In our cases, $4(14.3 \%)$ of the lacerations in stage 2 were smaller than one $\mathrm{cm}$, and $5(17.8 \%)$ were larger than one $\mathrm{cm}$. The patients who were followed up with bed rest and urinalysis were discharged without any problems. There were $5(17.8 \%)$ cases with subcapsular hematoma. Hemodynamic follow-up and absolute bed rest for two weeks were applied to these patients and no 
Table 4: Distribution of Male and Female genital injuries by trauma types.

\begin{tabular}{|c|c|c|c|c|c|c|c|}
\hline \multicolumn{8}{|c|}{ Trauma Types } \\
\hline & & $\begin{array}{l}-1 \mathrm{mF} \\
\mathrm{n}(\%)\end{array}$ & $\begin{array}{l}+1 \mathrm{mD} \\
\mathrm{n}(\%)\end{array}$ & $\begin{array}{l}\text { ICTA } \\
\text { n (\%) }\end{array}$ & $\begin{array}{l}\text { NCTA } \\
\text { n (\%) }\end{array}$ & $\begin{array}{l}\text { PCTI } \\
\text { n (\%) }\end{array}$ & $\begin{array}{c}\text { İatrogenic } \\
\text { n (\%) }\end{array}$ \\
\hline \multirow{11}{*}{ Male Genital } & None & $84(33.1)$ & 21(8.3) & $14(5.5)$ & $17(6.7)$ & $4(1.6)$ & $2(.8)$ \\
\hline & SSD & $28(11)$ & $5(2)$ & $2(.8)$ & $7(2.8)$ & $1(.4)$ & $0(0)$ \\
\hline & so & $8(3.1)$ & $4(1.6)$ & $0(0)$ & $3(1.2)$ & $0(0)$ & $0(0)$ \\
\hline & RTS & $8(3.1)$ & $0(0)$ & $0(0)$ & $0(0)$ & $0(0)$ & $0(0)$ \\
\hline & SR & $0(0)$ & $1(.4)$ & $0(0)$ & $0(0)$ & $2(.8)$ & $0(0)$ \\
\hline & $\mathrm{TL}$ & $14(5.5)$ & $1(.4)$ & $2(.8)$ & $5(2)$ & $0(0)$ & $0(0)$ \\
\hline & TR & $0(0)$ & $0(0)$ & $1(.4)$ & $1(.4)$ & $0(0)$ & $0(0)$ \\
\hline & PL & $4(1.6)$ & $4(1.6)$ & $0(0)$ & $5(2)$ & $3(1.2)$ & $1(.4)$ \\
\hline & PF & $0(0)$ & $0(0)$ & $0(0)$ & $1(.4)$ & $0(0)$ & $0(0)$ \\
\hline & PR & $0(0)$ & $0(0)$ & $0(0)$ & $1(.4)$ & $0(0)$ & $0(0)$ \\
\hline & Total & $146(57.5)$ & $36(14.2)$ & $19(7.5)$ & $40(15.7)$ & 10(3.9) & $3(1.2)$ \\
\hline \multirow{7}{*}{$\begin{array}{l}\text { Female } \\
\text { Genital }\end{array}$} & Yok & $130(51.2)$ & $26(10.2)$ & $14(5.5)$ & $34(13.4)$ & $5(2)$ & $3(1.2)$ \\
\hline & PSD & $14(5.5)$ & $2(.8)$ & $2(.8)$ & $1(.4)$ & $0(0)$ & $0(0)$ \\
\hline & PR & $0(0)$ & $5(2)$ & $2(.8)$ & $2(.8)$ & $0(0)$ & $0(0)$ \\
\hline & $\mathrm{VL}$ & $0(0)$ & $3(1.2)$ & $1(.4)$ & $3(1.2)$ & $0(0)$ & $0(0)$ \\
\hline & VR & $1(.8)$ & $0(0)$ & $0(0)$ & $0(0)$ & $4(1.6)$ & $0(0)$ \\
\hline & $\mathrm{V} / \mathrm{HR}$ & $1(.8)$ & $0(0)$ & $0(0)$ & $0(0)$ & $1(.8)$ & $0(0)$ \\
\hline & Total & $146(57.5)$ & $36(14.2)$ & 19(7.5) & $40(15.7)$ & 10(3.9) & $3(1.2)$ \\
\hline
\end{tabular}

Table 5: Correlation of univariate vs. multivariate analysis with variables of trauma.

\begin{tabular}{|c|c|c|c|c|c|}
\hline \multicolumn{6}{|c|}{ Trauma Types } \\
\hline \multirow{9}{*}{ Spearman's rho Correlation } & \multirow{9}{*}{ Trauma } & & $n$ & $r$ & $\mathrm{p}$-value \\
\hline & & kidney & 254 & .275 & $.001 *$ \\
\hline & & Ureter & 254 & .303 & $.001 *$ \\
\hline & & Bledder & 254 & .297 & $.001 *$ \\
\hline & & Urethra & 254 & .379 & $.001^{*}$ \\
\hline & & Male Genital & 254 & .214 & $.001 *$ \\
\hline & & Female Genital & 254 & .242 & $.001^{\star}$ \\
\hline & & Age & 254 & .006 & .922 \\
\hline & & Gender & 254 & -.090 & .153 \\
\hline
\end{tabular}

${ }^{\star} p<0.05$.

complication was observed. One of the $2(2.1 \%)$ patients with Type 4 injury was followed-up nonoperatively. In the other case, laceration repair was performed surgically. Nephrectomy was not needed in any case with renal trauma.

Traumatic ureteral injuries are rarely seen due to their good protection by the structures around the ureter and small size. It constitutes $1 \%$ of all genitourinary injuries. Ureters are usually the result of iatrogenic and penetrating injuries [20]. It is more common in children than in adults. The most common injured surface is the ureteropelvic junction and $4 \mathrm{~cm}$ portion of the proximal ureter. There is no hematuria in $1 / 3$ of the cases. Injury can easily be overlooked $[18,19,21,22]$.

In our study, the ureteral injury was observed in $8(3.6 \%)$ cases among all trauma cases. Two of the cases had Type 4 . The other six cases were associated with renal injury and were seen in the ureteropelvic junction. In patients with complete rupture, a double J catheter was inserted surgically and an end-to-end primary anastomosis was performed. The other six patients underwent cystoscopy and a double J catheter was inserted and followed-up with bed rest.

Blunt, penetrating or iatrogenic injuries of the bladder can be encountered. Bladder rupture is a common type of injury. It occurs in multiorgan injuries in full bladder, penetrating trauma in the tracheal bladder or pelvic bone fractures. Bladder trauma is seen in $5-10 \%$ of pelvic fractures. Pelvic fracture is present in almost all cases with bladder injury $[2,7,23]$. In minor injuries, spontaneous recovery may occur in 1-2weeks. Major injuries require surgical intervention [2,23,24].

In our study, there were $24(9.4 \%)$ cases with bladder injury. One of these cases was iatrogenic as a result of bladder catheterization, two cases were sharp object injury due to falling on a tree, and all other cases developed as a result of blunt trauma. All blunt traumatic bladder injuries were detected to be accompanied by pelvic fracture. In 13 of these 24 cases, Type 1 was present and catheter drainage and bed rest were applied until hematuria disappeared. 7(2.8\%) cases with Type 2 bladder injury were detected. These patients were applied for primary surgical repair and drainage. To uncomplicated Type 4A 4(1.6\%) cases, catheter drainage was applied on average for two weeks. Cystography was performed in all cases treated for bladder perforation and the patients were discharged without any complications.

Blunt abdominal traumas are the most common cause of posterior urethral injuries. Most of these injuries are together with pelvic fractures with $95 \%$. Anterior urethral injuries are usually the result of traumas such as the bulbous urethra being crushed on the pubic bone. In general, iatrogenic injuries occur during traumatic catheter insertion attempts of the anterior urethra [25]. Except for the iatrogenic injuries of the urethra, almost all are accompanied by pelvic fractures $[2,26]$.

In our study, we detected urethral injury in $20(7.9 \%)$ child cases with urogenital trauma. Three of these cases were iatrogenic, three were due to SOI, while in all other cases there was blunt trauma such as falling and traffic accident. 
Pelvic fracture and hematuria were present in cases except for iatrogenic and SOI. Six cases with Type 3 urethral rupture were inserted foley catheter under scopy, and followed-up. To one case with Type 5 urethral rupture, the urethral repair was performed on foley catheters surgically. The case was followed-up with suprapubic drainage. After the foley catheter was inserted, the patients were checked with urethrogram for leakage and no leakage was observed. Of the nine patients with anterior urethral injury, four had catheter insertion and five patients were only followed-up. No patient needed urethroplasty.

$0.4 \%$ to $8 \%$ of childhood traumas include genital traumas [23]. Most of these traumas do not require surgical treatment [6]. Falling from a height in a horse riding manner, traffic accidents, cycling, and playing equipment, sports trauma are the most common causes of genital organ injuries in this age group $[24,25]$. In female children, genital organ injury can easily be occurred due to tissue fragility in the prepubertal period [25]. While anterior urethra may be affected in traumas involving the penis in male children, the urethra is rarely affected by female children since it is short and immobile $[8,9]$.

In our study, few minor traumas require surgery in parallel with the literature. In males, scrotal were seen as the most common, while perineum skin lesions were seen in females.

Male genital injuries are mostly seen as a result of blunt traumas and they are the injuries that the scrotum and testicles are more affected. Testicular rupture can be difficult to understand since even mild traumas may cause edema and ecchymosis in the scrotum. Besides, it is possible to encounter situations where the scrotum is opened, the testicles are out of the scrotum and the testicles are completely separated. Scrotum skin lacerations are seen as the most common in genital area injuries. Also, the accompanying penile skin lesions are not few. In these cases, the ruptures of the penis corpus cavernosum should be considered. Penetration or blunt penile injuries are usually accompanied by urethral injuries [1]

In our study, there were $69(27.2 \%)$ cases with male genital organ injury. In three of these cases, the scrotal rupture was observed. Primary surgical repair was performed. All other cases required minor surgery and short-term follow-up. Bilateral total testicle and scrotal rupture were found in 2 of 24 cases $(9.4 \%)$ with a testicular injury. The severe pelvic fracture was also present in these cases occurred as a result of a traffic accident. By plastic surgery and pediatric surgery, primary surgical repair and reimplantation were performed in these two cases. After treatment, almost complete recovery was seen in one testicle of both cases, while atrophy was developed in the other two testicles. 19(7.5\%) cases with penile trauma were detected. The penile fracture was seen in one of these trauma cases and penile rupture in another. In the penile fracture, the hematoma was emptied, bed rest and elevation were applied. Surgical debridement and grafting were performed in penile rupture. Skin integrity was achieved. Bed rest was applied.

Genital injuries in girls are generally falling to a hard place where their legs were open, traffic accidents, sexual assaults and penetrating injuries [27]. In our study, no cases were requiring serious intervention in girls. In two of the total of 42cases $(16.5 \%)$ vaginal tear accompanied by hymenal tear was detected. Primary repair was performed. The minor repair was performed in other cases. No complication was observed in any of the cases.

As a result, urogenital system injuries can be seen in patients admitted to the emergency department due to trauma. Since these traumas may accompany multiorgan injuries, accurate evaluation can reduce potential complications. Hematuria is a valuable finding in the trauma of the urogenital system, however, its absence does not exclude the possibility of urological injury. Patients whose injuries are limited with renal parenchyma and having unimpaired hemodynamics can be followed-up with nonoperative treatment. Double J catheter is sufficient in the treatment for the partial ureteral injury, while the surgical repair is required for complete injuries Catheter drainage is sufficient for extraperitoneal bladder injuries and minor intraperitoneal bladder injuries, however, intraperitoneal major injuries require surgical repair. In patients with blunt trauma pelvic fractures, the possibility of bladder injury should not be forgotten.

The association between the form of trauma and the degree of organ injury is a guide in the selection of diagnostic methods. The classification of urogenital damages helps to select appropriate treatment and predict outcomes. Also, standardization in diagnosis will bring standardization in treatment. A careful examination is essential not to overlook minor genital and perineal traumas, besides the major urogenital trauma.

\section{Limitations of the study}

The most important limitation of the study was that it is single centered and retrospective. For this reason, difficulty was experienced in attaining some data. Some of these were; not coming back for control after admission to the emergency department, and the difficulty in accessing the urography and computed tomography results were other limitations. The fact that trauma score was not performed, other multiple traumas could not be included in the study and the medication use history that could affect its prognosis could not be reached were among the most important limitations.

\section{Conclusion}

Urogenital organ injuries, which constitute a small part of childhood traumas, are specialized issues with a multitude of etiologic factors, rapid psychological impact in children and legal aspects. Protection of post-traumatic organ functions of children who will form the future increases the importance of the treatment method to minimize the possible complications and provide good rehabilitation.

\section{References}

1. Koltuksuz U, Gürsoy MH (1998) Genitourinary Trauma in Children. J of Turgut Özal Medical Center 5: 97-104.

2. McAleer IM, Kaplan GW (1995) Pediatric Genitourinary Trauma. Urol Clin North Am 22: 177-188. Link: http://bit.ly/32HYhp5 
3. Synder HM, Caldamone AA (1986) Genitourinary injuries. Welch KJ, Randolph JG, Ravitch MM, et al. (eds). Pediatric Surgery. Chicago, Year Book Medical Publishers 174-185.

4. Stevenson J, Battistella FD (1994) The 'one-shot' intravenous pyelogram: Is it indicated in unstable trauma patients before celiotomy? J Trauma 36: 828 834. Link: http://bit.ly/2VB8X7f

5. Palmer LS, Rosenbaum RR, Gershbaum MD, Kreutzer ER (1999) Penetrating ureteral trauma at an urban trauma center: 10- year experience. Urology 54 34-36. Link: http://bit.ly/32HP5RA

6. Tarman GJ, Kaplan GW, Lerman SL, McAleer IM, Losasso BE (2002) Lower genitourinary injury and pelvic fractures in pediatric patients. Urology 59: 123 126. Link: http://bit.ly/3csuYeP

7. Gabriel NM, Clayton M, Starling SP (2009) Vaginal laceration as a result of blunt vehicular trauma. J Pediatr Adolesc Gynecol 22: 166-168. Link: http://bit.ly/2PEWplh

8. Husmann DA, Boone TB, Wilson WT (1993) Management of low-velocity gunshot wounds to the anterior urethra: The role of primary repair versus urinary diversion alone. J Urol 150: 70-72. Link: http://bit.ly/2PFpwLB

9. Okur H, Küçükaydın M, Kazez A, Turan C, Bozkurt A (1996) Genitourinary tract injuries in girls. Br J Urol 78: 446-449. Link: http://bit.ly/32DNaOr

10. Moore EE, Shackford SR, Pachter HL, McAninch JW, Browner BD, et al. (1989) Organ injury scaling: spleen, liver, and kidney. J Trauma 29: 1664-1666. Link: http://bit.ly/2wWKcls

11. Cooper A, Barlow B, DiScala C, String D (1994) Mortality and truncal injury: the pediatric perspective. J Pediatr Surg 29: 33-38. Link: http://bit.ly/2TyCvzM

12. Marc IR (1995) The Injured Child, in O’Neill, Jr AJ, Grosfeld JL, Fonkalsrud EW Coran AG (eds): Essentials of Pediatric Surgery, Chap 17, Mosby-Year book, USA 183-189.

13. Hu X, Wesson DE, Logsetty S, Spence LJ (1994) Functional limitations and recovery in children with severe trauma: a one-year follow-up. J Trauma 37: 209-213. Link: http://bit.ly/2x4Mtlb
14. Tepas III JJ, DiScala C, Ramenofsky ML, Barlow B (1990) Mortality and head injury: The pediatric perspective. J Pediatr Surg 25: 92-96. Link: http://bit ly/2lcHjWt

15. Özyurt M (1983) Child Urology. İstanbul, İ Akgün Foundation Printing House 275

16. Frame SB, McSwain NE (1983) Retroperitoneal trauma. Infect in Surg 8: 3

17. Cheng DL, Lazan D, Stone N (1994) Conservative treatment of type III rena trauma. J Trauma 36: 491-494. Link: http://bit.ly/2Tvq33L

18. Kocakoç E (2014) Abdominal Radiology. Ankara: World Bookstore.

19. Soto JA, Anderson SW (2012) Multidetector CT of blunt abdominal trauma Radiology 265: 678-693. Link: http://bit.ly/32loNig

20. European Society for Paediatric Urology. Pediatric Urology Webbook. 3rd Edition, published on 20/10/15

21. Mama N, Jemni H, Achour NA, Sidiya OC, Kadri K, et al. (2012) Abdominal Trauma Imaging. Derkel F, Editor. Abdominal Surgery. Intech, open access. Link: Link: http://bit.ly/2Tv5K6D

22. El Wakeel AM, Habib RM, Ali AN (2015) Role of CT in the Evaluation of Blunt Abdominal Trauma. Int J Med Imaging 3: 89-93. Link: http://bit.ly/2lgeW9D

23. Galisteo Moya R, Noqueras Ocaña M, Tinaut Ranera FJ, de la Fuente Serrano A, Gutiérrez Tejero F, et al. (2002) External genital injuries during childhood Arc Esp Urol 55: 813-818. Link: http://bit.ly/3ajgNGL

24. Bertini JE, Corriere JN (1988) The etiology and management of genital injuries J Trauma 28: 1278-1281. Link: http://bit.ly/2TbiH6C

25. Kiracofe HL, Pfister RR, Peterson NE (1975) Management of nonpenetrating distal urethral trauma. J Urol 114: 57-62. Link: http://bit.ly/2PyATFd

26. Murphy JP (1990) Genitourinary trauma. Ashcraft KW (ed). Pediatric Urology. Philadelphia, WB Saunders Company 437-447.

27. Scheidler MG, Schultz BL, Schall L, Ford HR (2000) Mechanisms of blunt perineal injury in female pediatric patients. J Pediatr Surg 35: 1317-1327. Link: http://bit.ly/38imwet
Discover a bigger Impact and Visibility of your article publication with Peertechz Publications

Copyright: @ 2020 Güney C, et al. This is an open-access article distributed under the terms of the Creative Commons Attribution License, which permits unrestricted use, distribution, and reproduction in any medium, provided the original author and source are credited.

Citation: Güney C, Coşkun A (2020) Classification in the diagnosis and treatment of organ damage caused by urogenital trauma in children. Arch Urol Res 4(1): 001-006. DOI: https://dx.doi.org/10.17352/aur.000007 